\title{
Taxonomical Review of the Subfamily Ophioninae (Insecta: Hymenoptera: Ichneumonidae) from Korea II. Genus Ophion Fabricius
}

\author{
Ki-Beom Kim, Kyong-In Suh and Jong-Wook Lee* \\ Department of Biology, Yeungnam University, Gyeongsan 712-749, Korea
}

\begin{abstract}
Korean species of the genus Ophion Fabricius are reviewed. Eight species are recognized including two species new to Korea (O. ainoicus Uchida, 1928 and O. choaspese (Uchida, 1954). We provide a key to the Korean Ophion and redescriptions, photographs, distributional data and host records of the newly recorded species.
\end{abstract}

Key words: Ophion, Ophioninae, Ichneumonidae, Korea

\section{INTRODUCTION}

The subfamily Ophioninae is a moderately large, cosmopolitan group comprising 32 genera in the world (Gauld, 1985). Members of the genus are known as useful economic insects because they mostly attack larvae of Noctuidae (Lepidoptera) as koinobiont endoparasitoids. Lee and Cha (2000) reported six genera and 27 species in the subfamily from Korea. Of these, two genera (Stauropoctonus Brauns, 1889 and Enicospilus Stephens, 1835) have already been reviewed (Lee and Kim, 2002; Lee et al., 2003), and genus Ophion is reviewed in this paper.

Since Kim (1955) reported four species of Korean Ophion, O. flavopictus Smith, 1874, O. fuscomaculatus Cameron, 1899, O. luteus (Linnaeus, 1758) and O. obscuratus Fabricius, 1798, for the first time in Korea. Lee and Kim (1980, 1983) added O. takaozanus Uchida, 1928 and O. okunii Uchida, 1928 in Korean fauna. Therefore, a total of six species of the group have been reported to date in Korea.

Ophion is easily distinguished from the other Ophioninae by the combination of the following characters: posterior transverse carina of mesosternum not complete, broadly interrupted in front of each middle coxa; basal part of radial vein straight, not thickened basally; notaulus usually distinct and moderately long.

In this study, we report two newly recorded species, $O$. ainoicus Uchida, 1928 and O. choaspese (Uchida, 1954), from Korea. We also provide a key to the species of Korean Ophion and descriptions, photographs, distributional data and host records of the newly recorded species.

\footnotetext{
*To whom correspondence should be addressed

Tel: 82-53-810-2376, Fax: 82-53-811-2376

E-mail: jwlee1@ynu.ac.kr
}

\section{MATERIALS AND METHODS}

Morphological terminology used in this study follows Gauld (1985). Specimens were examined using a stereo-microscope (Stemi SV 11 Apo; Carl Zeiss, Göttingen, Germany) and photographs produced with Zeiss AxioCam MRc5 digital camera system optimized with an i-delta imaging system (Image \& Microscope Technology Daejeon, Korea). The examined specimens are deposited in the Department of Biology, Yeungnam University in Korea.

Abbreviations for type information are as follows: TD: Type Depository, and TL: Type Locality.

\section{TAXONOMIC ACCOUNTS}

Family ${ }^{1} *$ Ichneumonidae Latreille, 1802

Subfamily ${ }^{2} *$ Ophioninae Shuckard, 1840

Genus ${ }^{3 *}$ Ophion Fabricius, 1798

Key to the species of the genus Ophion from Korea 1. Latero-marginal carinae of scutellum almost parallel.

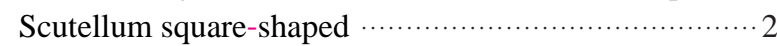

- Latero-marginal carinae of scutellum strongly convergent to the posterior. Scutellum triangle-shaped …............ 3

2. Ocelli contiguous from eye. Interocellar area reddish yellow. Last two abdominal segments comparatively long. Ovipositor not projected beyond apical tip of abdomen ....

Ophion fuscomaculatus Cameron

- Ocelli widely separated from eye. Interocellar area blackish brown (Fig. 2C). Last two abdominal segments short. Ovipositor projected beyond apical tip of abdomen Ophion choaspese (Uchida)

\footnotetext{
${ }^{1} *$ 맵시벌과, ${ }^{2} *$ 왕자루맵시벌아과, ${ }^{3}$ 왕자루맵시벌속
} 

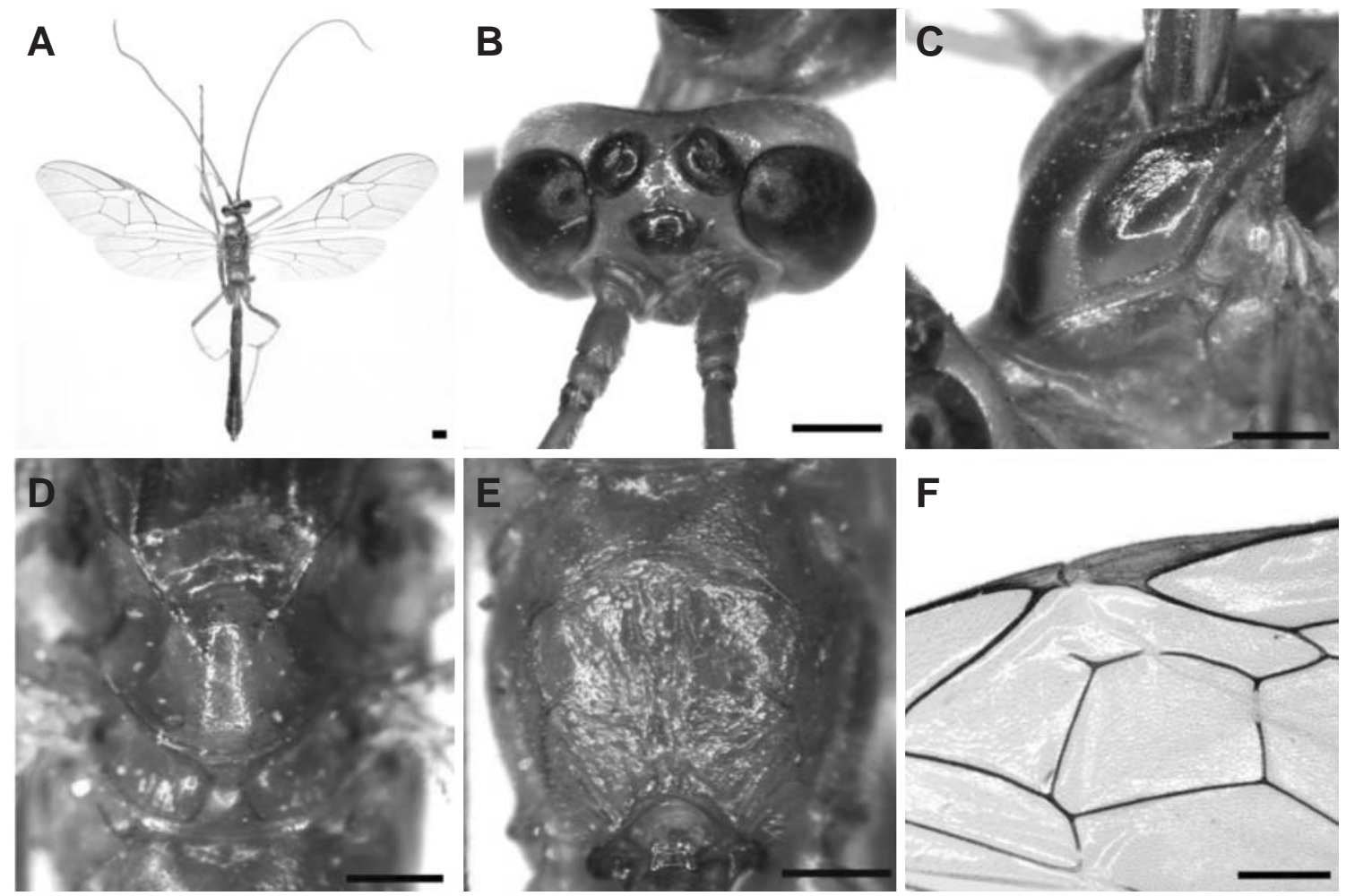

Fig. 1. Female of Ophion ainoicus. A, Body in dorsal view; $B$, Head in dorsal view; C, Prothorax in lateral view; $D$, Mesothorax in dorsal view; E, Propodeum in dorsal view; F, Fore wing in part. Scale bars $=1 \mathrm{~mm}(A, F), 0.5 \mathrm{~mm}(B-E)$.

3. Notauli longer than $0.5 \mathrm{x}$ of the mesoscutum length and very deep. Mesoscutum with three linear blackish brown markings along notauli (Fig. 1C)

Ophion ainoicus Uchida

- Notauli shorter than $0.5 \mathrm{x}$ of the mesoscutum. Mesoscutum color variable

\section{.4}

4. Mesocutum and propodeum blackish brown ….........5

- Mesocutum and propodeum not as above ….............. 6

5. Latero-marginal carina longer than $0.5 x$ of the scutellum length. Mesopleural subalar prominence line indistinct. The number of distal hamuli of hind wing less than $9 \ldots$.

Ophion okunii Uchida

- Latero-marginal carina shorter than $0.5 x$ of scutellum length. Mesopleural subalar prominence line distinct. The number of distal hamuli of hind wing more than 10

Ophion takaozanus Uchida

6. Head, thorax and propodeum with irregular whitish yellow markings. Apical segments of abdomen with medio-longitudinal whitish yellow delineated markings in each lateral sides …................ Ophion obscuratus Fabricius

- Head, thorax, propodeum and abdomen not as above …7

7. Thorax without distinctly delineated yellow markings .....
Ophion luteus (Linnaeus)

- Thorax with distinct and irregular yellow markings

Ophion flavopictus Smith

$1 *$ Ophion ainoicus Uchida, 1928 (Fig. 1A-F)

Ophion ainoicus Uchida, 1928. 21: 209, Type: 우, TL: Japan, TD: Hokkaido University.

Description of female. Body length $18 \mathrm{~mm}$. Fore wing length $15 \mathrm{~mm}$.

Face width $1.35 x$ height of face and clypeus. Inner margin of eyes divergent. Ocelli large (Fig. 1B). Frons weakly convex at the center. Face densely punctuated and convex. Clypeus weakly convex and its margin with a fringe of closely spaced bristles. Mandible broad; upper tooth not twisted and lower tooth almost equal in length. Antenna with 62 flagellar segments (Fig. 1A). Occipital carina complete and joining hypostomal carina above mandibular base. Pronotum spiracle partially covered (Fig. 1C). Mesoscutum with dense punctures and three linear blackish brown markings along the notauli; notauli long and strongly impressed. Latero-marginal carina of scutellum short. Fore wing veins of transverse

\footnotetext{
$1 *$ 등줄왕자루맵시벌
} 

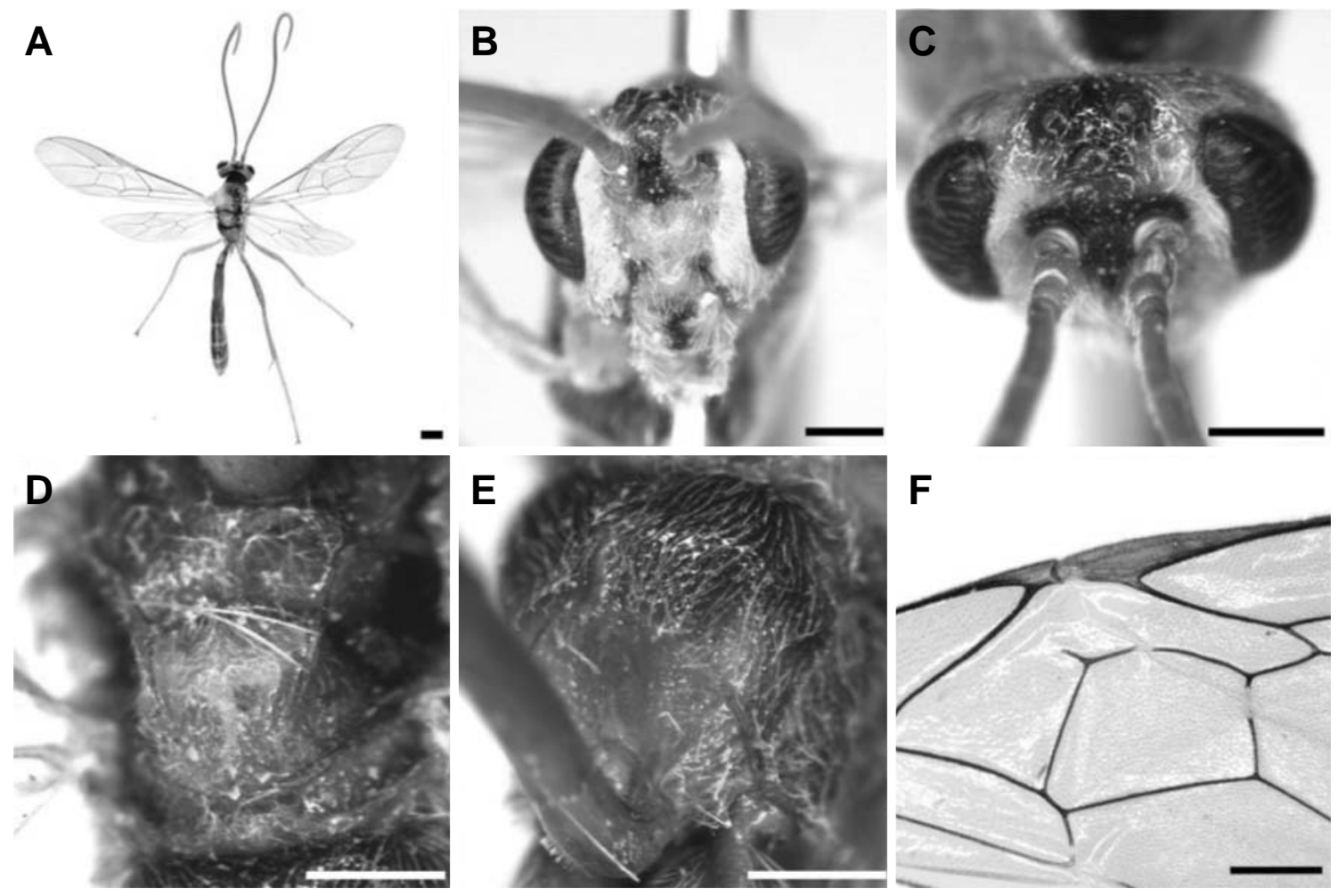

Fig. 2. Female of Ophion choaspese. A, Body in dorsal view; $B$, Head in frontal view; $C$, Head in dorsal view; $D$, Mesothorax in dorsal view; $E$, Propodeum in dorsal view; F, Fore wing in part. Scale bars $=1 \mathrm{~mm}(A, F), 0.5 \mathrm{~mm}(B-E)$.

brace in ratio of $1: 1.88: 2.73$ (Fig. 1F). Hind wing with 4 basal hamuli and 8 distal hamuli. Legs slender; front tibial spur with membranous flanges. Tarsal claws strongly pectinated. Abdomen compressed laterally. Spiracle of first tergite at the posterior to the middle. Ovipositor short.

Color: Body yellowish brown except eyes, tip of mandible, wings, three linear markings along notauli and apical 0.5 of segment 4 to apex of abdomen blackish brown.

Materials examined. Total 3 specimens. Korea: Gyeongsangnam-do, Namhae-gun, Namsang-ri, Mt. Mangun, 16-17 May 1999 (J.H. Kim) $2 \sigma^{7}$; Namhae-gun, Namsang-ri, Mt. Mangun, 16-17 May 1999 (J.W. Choi) 1 우.

Distribution. Korea, Japan.

Host. Unknown.

\section{${ }^{1} *$ Ophion choaspese (Uchida, 1954) (Fig. 2A-F)}

Stenophthalmus choaspese Uchida, 1954. 18: 68. Type: $\sigma^{7}$, TL: Japan, TD: Hokkaido University.

Description of male. Body length $12 \mathrm{~mm}$, Fore wing length $9 \mathrm{~mm}$.

Face width $1.62 x$ height of face and clypeus. Inner margin of eyes divergent. Ocelli small (Fig. 2C). Frons weakly convex at center. Face densely punctuated and convex (Fig. 2B). Clypeus weakly convex and its margin with a fringe of closely spaced bristles. Mandible broad; upper tooth not twisted and lower tooth almost equal in length. Antenna with 39 flagellar segments (Fig. 2A). Occipital carina complete and joining hypostomal carina above mandibular base. Pronotum spiracle partially covered. Mesoscutum with dense punctures; notauli very short and weakly impressed. Latero-marginal carina of scutellum nearly complete and long (Fig. 2D). Fore wing veins of transverse brace in ratio of $1: 1.43: 2.23$ (Fig. 2F). Hind wing with 4 basal hamuli and 7 distal hamuli. Cu1 of hind wing shorter than cua. Legs slender; front tibial spur with membranous flanges. Tarsal claws pectinated. Abdomen compressed laterally. Spiracle of the first tergite at posterior to middle.

Color: Body yellowish brown except eyes, tip of mandible, the center of vertex and frons, post gena, lateral sides of mesothorax and basal part of propodeum blackish brown.

Materials examined. Total 4 specimens. Korea: Seoul, Seongbuk-gu, Jeongneung4-dong, Mt. Bukhan, 6 May 1987 (J.W. Lee) $1 \sigma^{7}$; Jeollabuk-do, Muju-gun, Seolcheon-myeon, Dugil-

\footnotetext{
1*큰방패왕자루맵시벌
} 
ri, Gucheondonggyegok, 21 May 1983 (J.W. Lee) $2 \sigma^{\top}$; Gangwon-do, Samcheok-si, Hajang-myeon, Mt. Duta, 21 May 2005 (J.W. Lee).

Distribution. Korea, Japan.

Host. Choaspes benjaminii Guérin-Meneville (Lepidoptera: Hesperioidea).

\section{ACKNOWLEDGEMENTS}

This work had financial support from the Korean Ministry of Environment as “The Eco-technopia Project”.

\section{REFERENCES}

Gauld, I.D., 1985. The phylogeny, classification and evolution of parasitic wasps of the subfamily Ophioninae (Ichneumonidae). Bull. Br. Mus. (Nat. Hist.), Entomol. Ser., 51(2): 61-185.

Kim, C.W., 1955. A study on the Ichneumon-flies in Korea. (in Korean with German summary). Comm. These 15th Anniv. Korea Univ., Seoul, pp. 423-498.

Lee, J.W. and J.Y. Cha, 2000. Illustrated Catalogue of Ichneumonidae in Korea (1. Anomaloninae, Eucerotinae, Meso- chorinae, Metopiinae, Ophioninae, Paxylommatinae, Tryphoninae). In Park, K.T., ed., Insects of Korea. Korea Research Institute of Bioscience and Biotechnology, Daejeon, pp. 1-276.

Lee, J.W. and C.W. Kim, 1980. A taxonomical study on the Korean Ophioninae (Hymenoptera: Ichneumonidae). Korean J. Entomol., 10(1): 9-18.

Lee, J.W. and C.W. Kim, 1983. Studies on the Ichneumonidae from Korea. I. Six unrecorded species of Ophioninae (Hymenoptera: Ichneumonidae). Korean J. Entomol., 13(1): 11-14.

Lee, J.W. and K.B. Kim, 2002. Taxonomical review of the subfamily Ophioninae (Hymenoptera: Ichneumonidae) 1. Genus Stauropoctonus Brauns. Korean J. Entomol., 32(2): 81-86.

Lee, J.W., K.B. Kim, J.C. Jung, K.H. Jeun and J.H. Kim, 2003. Two Unrecorded species of the Genus Enicospilus (hymenoptera: Ichneumonidae: Ophioninae: Enicospilini) from Korea. Korean J. Entomol., 33(1): 59-63.

Uchida, T., 1928. Zweiter Beitrag zur Ichneumoniden-Fauna Japans. J. Fac. Agric. Hokkaido Univ., 21(5): 177-297.

Uchida, T., 1954. Vier neue Schlufwespen als Schmarotzer der Tagfalter (Hymenoptera: Ichneumonidae). Insecta Matsumurana, 18(3-4): 67-72.

Received October 22, 2008 Accepted November 7, 2008 